\section{Lust und Schmerz}

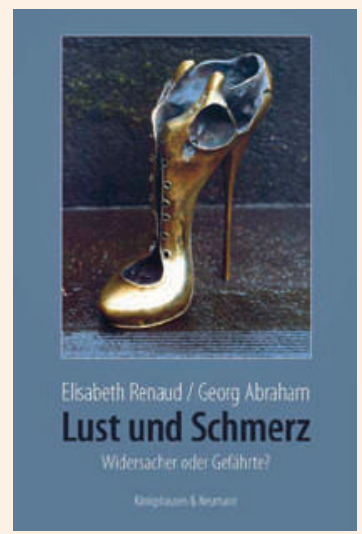

Elisabeth Renaud

Georg Abraham,

Lust und Schmerz

Widersacher oder Gefährte?

Würzburg: Königshausen \& Neumann; 2012.

120 Seiten. $28.40 \mathrm{CHF}$

ISBN 978-3-8260-4939-2

Ein ungewöhnliches Thema, reich an Paradoxien und noch unergründeten Aspekten, haben die beiden Autoren dieses Buchs ausgewählt. Über Schmerz und Leid wurde schon viel geschrieben, aber was sie anstreben, ist ein Vergleich zwischen Schmerz und Lust. Elisabeth Renaud, aus Zürich, ist Philologin, Übersetzerin und Musikkritikerin. Georges Abraham ist Psychiater, Neurologe, Psychoanalytiker, Philosoph und Sexologe. Er lebt und praktiziert in Genf.

Das Buch ist in acht Kapitel unterteilt, ohne Angabe des jeweiligen Autors. Die Rezensentin hat sich gefragt, wieso es zu dieser ungewöhnlichen Entscheidung kam. Es bleibt dem Leser überlassen zu erraten, wer zu welchem Thema beigetragen hat. Die Kapitel befassen sich mit Sinneswahrnehmungen, Perversionen, Lust und Schmerz in der Kunst, Schöpfung und Kultur, heimtückischer Lust, mit dem Verhältnis zur Religion, Lust- und Schmerzspielen im Reiche der Sklaven, und Identität und Identifikation. Medizinische, psychoanalytische, philosophische und kunsthistorische Gedanken wechseln sich ab, kreuzen und bereichern sich gegenseitig. Es werden Aspekte der Lust und des Schmerzes untersucht und durchleuchtet. Ihre Unterschiede bilden den roten Faden des Buchs, wobei die Lust mehr Rätsel aufwirft als der Schmerz.

Die Lust, so eine der grundlegenden Thesen, ist flüchtig und immer gefährdet. Angenehme Gefühle sind von kürzerer Dauer als unangenehme. «Die Lust ist nicht stets auf Anhieb als solche zu erkennen, denn sie kann sich weder zeigen noch sich ereignen, wenn nach ihr verlangt oder auf sie gewartet wird, noch sich unverhofft einstellen» (S. 49). Ihre Vergänglich- keit bringt es mit sich, dass sie zwar gesucht, aber nicht willentlich gefunden oder gesteuert werden kann. Die bewusste Suche nach ihr kann in Mechanik ausarten. So in den Perversionen, bei denen es darum geht «sich zu versichern, dass ein stets sich wiederholendes Objekt vorhanden ist» (S. 48). Die Autoren schlagen vor, anstatt Perversionen den Begriff der Paraphilie zu verwenden, der weniger diskriminierend ist. Daraus folgt eine neue Definition: «Der paraphile Mensch fühlt sich im Allgemeinen nicht im Geringsten als ein kranker (...)., sondern hat eine mit Impulsen besessene Persönlichkeit, (...); er hat, seiner eigenen Meinung nach eher eine aussergewöhnliche sexuelle Veranlagung, die ihn veranlasst, die normale Sexualität zu verachten» (S. 51). Die Paraphilie hat mit Lust und Erotik nichts zu tun.

Die Autoren gehen in ihren Überlegungen keineswegs von einem Normbegriff aus. Sie zeigen, ohne zu werten, wie relativ dieser letztendlich ist. «Ein authentisches Gleichgewicht (...) ist auf keinen Fall nur durch die Physiologie, durch ein standardisiertes Funktionieren des menschlichen Organismus gewährleistet, sondern wird eher durch eine Verflechtung von Normen und Abweichungen, von der Physiologie und Pathologie wie im übrigen von Lust und Schmerz, vom Vergnügen und Leid garantiert» (S. 10). Hier sprechen sich die Autoren, entgegen dem Strom der heutigen biologischen Psychiatrie, eindeutig und überzeugend für den Reichtum des psychischen Lebens aus, indem sie auch dem Schlaf und den Träumen eine besondere Bedeutung zuschreiben: «Die echten Bilder unseres Inneren, die unsere $\mathrm{Au}$ gen wahrnehmen, sind immer diejenigen des Traums» (S. 114). Die Emotionen und das Imaginäre sind in diesem Zusammenhang eminent wichtig. Der Zugang zu ihnen ermöglicht einen fruchtbaren therapeutischen Dialog, der auf der Intensität des Erlebens basiert.

Ein wichtiger Unterschied zwischen Lust und Schmerz besteht darin, dass der Schmerz mitgeteilt und mitempfunden werden kann. Er wirkt dadurch sozial verbindend und erweckt Solidarität. Die Lust hingegen wird individuell genossen und weckt eher den Neid. Sie ist nicht leicht zu teilen. «Sie trägt unsere grundsätzliche Eigenartigkeit zur Schau, unterstreicht unsere Vorlieben und unser inneres Sein» (S. 213). Die Lust hat also eine antisoziale Tendenz, die es schwieriger macht, sie anzuerkennen. Wir bewegen uns in einer Dynamik zwischen dem Bedürfnis nach Anpassung, um dazuzugehören, und dem Bemühen, uns von den anderen abzuheben, um die ureigene Identität zu bewahren.

Der Umgang mit der Lust wird in der Geschichte, vom antiken Griechenland über das Christentum mit dem mittelalterichen Satanund Hexenkult, bis zur Gegenwart zurückverfolgt. Der Lust der Götter in der griechischen Mythologie waren keine Grenzen gesetzt, und die Menschen, die diese Geschichten erfunden hatten, gingen ihr mit Leidenschaft nach. Das Christentum setzte der Sexualität enge Grenzen. Einer der interessantesten Befunde dieses Buchs ist, dass die Sexualität an Lust verloren hat, seitdem es keine Verbote und Gebote mehr gibt. Verbote erhöhen die Bereitschaft zur Lust. Das Buch ist so reich an Beobachtungen und Überlegungen, dass es nicht einfach ist, es zusammenzufassen. In einem letzten Abschnitt mit dem Untertitel «Der entfaltete Mensch» greifen die Autoren ihren grundlegenden Gedanken nochmals auf: «Erfährt man eher ein Schicksal, das auf einer unerschöpflichen Verknotung von genetischen und epigenetischen Elementen besteht (...) oder schmiedet man sein eigenes Schicksal, wenigstens teilweise?» (S. 151). Wie kann mit dem Bedürfnis nach spontaner Erotik umgegangen werden? Eine Antwort lautet, dass die Sexualität im weitmöglichsten Sinne - auch die Liebe, das Verliebtsein, das Paarleben - dem Neuen und Unerwarteten offen bleibt. So kann das Selbst unabhängiger von Zwängen konstruiert werden. Es gehe darum, immer eine Balance zwischen dem Gewohnten, das Sicherheit gibt, und dem Neuen und Überraschenden zu finden. Das ist eine differenzierte Sicht des Lebens, die jeder Vereinfachung widersteht und andere Wege öffnet.

Nina Bakman, Zürich 